\title{
THE NATURE AND MECHANISM OF THE HEMOSTATIC BREAKDOWN IN THE COURSE OF EXPERIMENTAL HEMORRHAGIC SHOCK*
}

\author{
By RINALDO TURPINI † AND MARIO STEFANINI
}

(From the Joseph Stanton Memorial Laboratories of Saint Elizabeth's Hospital, and the Department of Medicine, Tufts University School of Medicine, Boston, Mass.)

(Submitted for publication May 20, 1958; accepted September 4, 1958)

A severe bleeding tendency, the most striking features of which are fibrinogenopenia and thrombocytopenia, has been reported in some obstetrical accidents, certain types of surgery, multiple replacement transfusions and other clinical conditions (1). The pathogenesis of this syndrome remains a matter of dispute, as various authors have stressed the role of either intravascular clotting or of fibrinolysis. Most likely, both mechanisms are important, although of different impact from case to case. Especially in obstetrical and surgical practice, one encounters instances where severe hemorrhage occurs because of major trauma to vessels or because of the presence of a large bleeding surface. In some of these patients, bleeding becomes progressively more severe, and the fibrinogenopenic syndrome develops. The role of hemorrhage itself, at least in aggravating the bleeding tendency and, in some cases, in possibly initiating fibrinogenopenia, has apparently not been fully considered. It is the purpose of this paper to discuss the hemostatic changes occurring in the course of severe hemorrhage with special reference to the pathogenesis of fibrinogenopenic states. ${ }^{1}$

Important changes of the coagulation mechanism during severe hemorrhage have been noted by many authors. Hewson (2) made the classical observation that "the blood which issued last coagulated first in animals and men being

\footnotetext{
* Supported by a grant-in-aid from the American Heart Association. Presented April 18, 1958, at the Annual Meeting of the American Physiological Society, Philadelphia, $\mathrm{Pa}$.

† Lederle Scholar in Medical Sciences, on leave of absence from the Department of Medicine, University of Pavia, Italy.

1 Fairly extensive unpublished work in dogs, showing essentially the same results as presented here, was completed in this Laboratory during $1956-57$ by Hector Marin, Leo Gagliardi and Mario Stefanini.
}

venesected." Von den Velden (3), while confirming this observation, thought that the hypercoagulability in the course of hemorrhage might be due to the entrance in the circulation of interstitial fluid carrying thromboplastic material. A different conclusion was reached by $\mathrm{McClintock}$ and Magers (4). They noted shortening of the clotting time in severely bled dogs. This, however, did not occur in previously splenectomized animals. Thus, they concluded that the splenic vasoconstriction which accompanies hemorrhage might cause entrance of thromboplastic agents within the blood stream. The shortening of the clotting time during hemorrhage has been confirmed more recently in cats (5) and in dogs (6). Animals have been shown to develop hypoprothrombinemia during and after bleeding (7), and widespread fibrin clots have been washed out from the pulmonary vessels of dogs following death due to irreversible shock (8). Parallel studies in man, performed in individuals who had suffered from recent severe hemorrhage, have given inconclusive results. No changes in the clotting time (9) performed by standard techniques, but prolongation of the sensitized clotting time (10), have been reported. Hypoprothrombinemia seems a fairly constant finding (9).

\section{MATERIALS AND METHODS}

A total of 45 New Zealand white rabbits of the average weight of $2.5 \mathrm{Kg}$. were used. The following technique was employed to induce hemorrhagic shock. An area of skin covering the central artery of the ear was first anesthetized by infiltration with 1 per cent Novocaine ${ }^{\circledR}$ solution to prevent reflex vasoconstriction. Forty $\mathrm{ml}$. of blood per kiloweight was then removed by gentle suction in cooled syringes through a 20 gauge needle inserted into the central artery of the ear, in an average time of 15 to 30 minutes. This amount represented approximately 70 to 80 per cent of the calculated blood volume. The loss of such percentage volume of blood has been shown to induce shock in the rabbit (11). In our study, pre- 


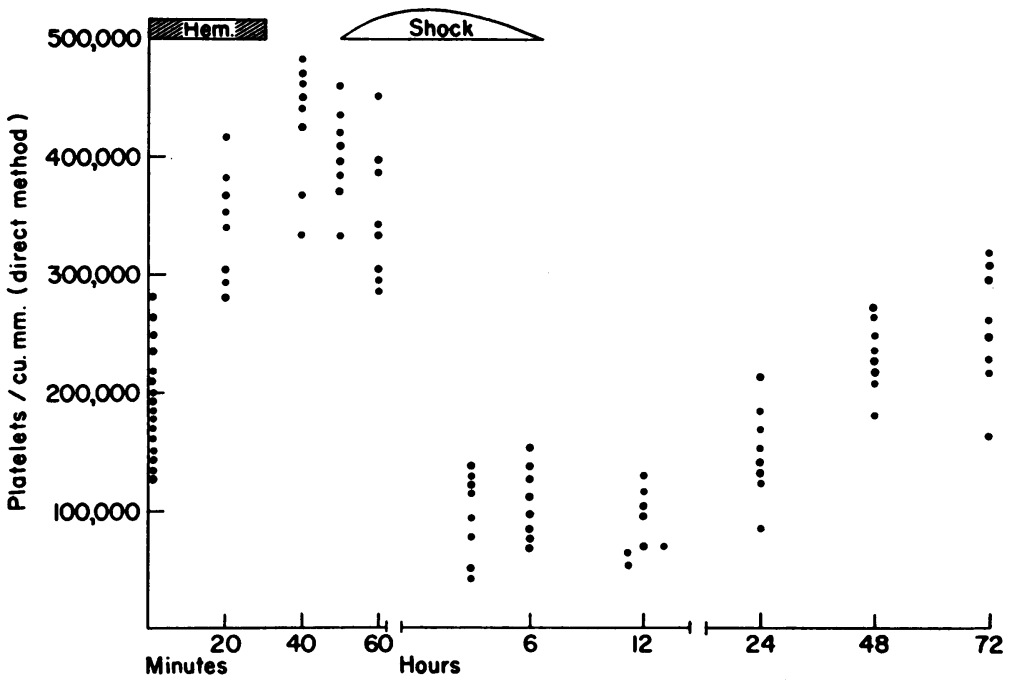

Fig. 1. Behavior of the Platelet Count During and Following Hemorrhagic Shock in Rabits

Note the considerable variations from animal to animal, which, however, do not invalidate the uniform trend of the results. A similar consideration applies to all figures in this article.

EARLY PHASE OF HEMORRHAGIC SHOCK: TGT $(7 \mathrm{Min}$.)

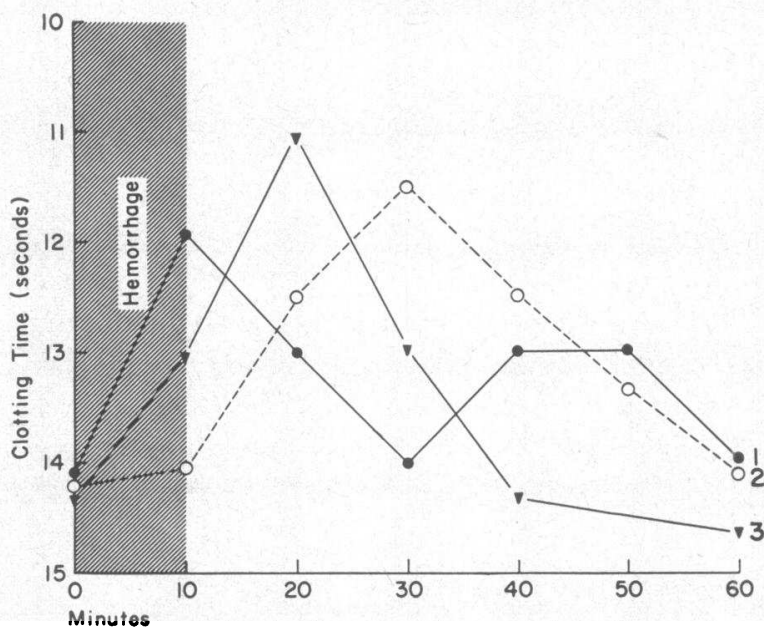

Fig. 2. Thromboplastin Generation in the Early Phase of Hemorrhagic Shock (See Text)

The values are those obtained after seven minutes of incubation of the reacting mixtures, and are from a single experiment. In each instance, platelets were obtained from human plasma for convenience, after preliminary experiments (R.A.T.) showed that their activity in the system could be substituted to that of rabbit platelets. Three experiments are described where plasma or serum from normal animals and animals in shock were used:1) normal plasma and shock serum; 2) shock plasma and normal serum; 3) shock plasma and serum. Shock plasma and serum both seemed to accelerate the formation and increase the yield of thromboplastin, suggesting the presence of a clotting accelerator, the nature of which is under investigation. sumptive indications of shock (prostration, extremely rapid heart rate) persisted for four to 10 hours. Blood was collected from the contralateral central artery of the ear before, during, and immediately and at various intervals of time after bleeding (every 10 minutes for the first hour and at 2, 4, 6, 24, 48 and 72 hours) until all values considered had returned to normal or near normal. Each time, $5 \mathrm{ml}$. of blood was collected in a siliconized syringe containing sodium oxalate at a final concentration of $0.01 \mathrm{M}$, and an additional $5 \mathrm{ml}$. in a plain glass syringe, for preparation of serum. The volumes of the test samples taken before, during and within the first 30 minutes of acute venesection were included in the calculation of the total volume of blood removed, as the continued bleeding probably contributed to the maintenance of the state of shock in the early phase of our experiments. Because of the technical difficulty involved in repeated venesections and also to prevent excessive removal of blood from a single animal, rabbits were divided into two groups. One group was studied in the early phase (up to one hour) and the other in the late phase (up to 72 hours). Studies included: direct platelet count (12) and observations of the morphologic appearance of platelets on a stained smear; generation of thromboplastin according to a standard technique (13) and using a modification with heterologous systems, where platelets were of human source and plasma and serum were supplied by an experimental or by a normal animal in various combinations; activity of plasma prothrombin (14) ; concentration of prothrombin (15) and of stable factor as proconvertin (factor VII) (15); concentration of labile factor (factor V) (16); and determination of plasma fibrinogen level (14).

The fibrinolytic activity of serum was studied with a number of techniques: $a$ ) A plate method, after addition 
TABLE I

Thromboplastin generation test (TGT) during and following hemorrhagic shock in rabbits*

\begin{tabular}{|c|c|c|c|c|c|c|c|c|c|c|}
\hline \multirow{2}{*}{$\begin{array}{l}\text { Incubation } \\
\text { time of } \\
\text { reagents } \\
\text { for TGT }\end{array}$} & \multicolumn{10}{|c|}{ Time after initiation of bleeding } \\
\hline & $\mathbf{0}$ & $10 \mathrm{~min}$. & $30 \mathrm{~min}$. & $1 \mathrm{hr}$. & $2 \mathrm{hr}$. & $6 \mathrm{hr}$. & $12 \mathrm{hr}$. & $24 \mathrm{hr}$. & $48 \mathrm{hr}$. & $72 \mathrm{hr}$. \\
\hline \multicolumn{5}{|c|}{$\begin{array}{l}\min . \\
\text { (A) Normal plasma and serum }\end{array}$} & \multicolumn{3}{|c|}{ clotting times (seconds) } & & & \\
\hline 1 & $42.3 \pm 6.2$ & $41.4 \pm 4.9$ & $47.3 \pm 5.1$ & $46.3 \pm 3.7$ & $42.7 \pm 2.9$ & $44.3 \pm 4.0$ & $43.2 \pm 2.8$ & $49.4 \pm 3.2$ & $43.1 \pm 3.4$ & $41.9 \pm 3.7$ \\
\hline 3 & $13.9 \pm 1.6$ & $14.2 \pm 1.9$ & $14.5 \pm 2.0$ & $14.1 \pm 1.9$ & $15.0 \pm 0.4$ & $14.2 \pm 0.9$ & $15.0 \pm 0.5$ & $14.0 \pm 1.4$ & $14.7 \pm 0.7$ & $15.3 \pm 0.4$ \\
\hline 5 & $12.7 \pm 1.7$ & $12.5 \pm 0.7$ & $12.6 \pm 1.1$ & $13.1 \pm 1.3$ & $13.6 \pm 0.8$ & $13.9 \pm 1.4$ & $14.3 \pm 2.0$ & $13.9 \pm 1.8$ & $14.0 \pm 1.6$ & $13.2 \pm 0.7$ \\
\hline 7 & $13.2 \pm 2.4$ & $13.0 \pm 1.7$ & $13.3 \pm 2.1$ & $13.7 \pm 2.8$ & $12.9 \pm 2.0$ & $13.2 \pm 1.7$ & $12.8 \pm 1.7$ & $13.4 \pm 2.4$ & $12.9 \pm 2.1$ & $13.1 \pm 1.4$ \\
\hline 9 & $13.7 \pm 2.1$ & $13.5 \pm 1.8$ & $13.4 \pm 0.9$ & $14.1 \pm 1.3$ & $14.5 \pm 2.3$ & $14.2 \pm 2.6$ & $13.9 \pm 0.8$ & $14.3 \pm 0.7$ & $13.8 \pm 1.2$ & $14.1 \pm 3.0$ \\
\hline 11 & $19.1 \pm 4.2$ & $20.4 \pm 5.0$ & $18.4 \pm 3.2$ & $20.7 \pm 2.7$ & $18.8 \pm 2.3$ & $19.4 \pm 2.0$ & $19.6 \pm 2.4$ & $20.3 \pm 3.0$ & $19.2 \pm 2.0$ & $21.6 \pm 2.7$ \\
\hline \multicolumn{11}{|c|}{ (B) Shock plasma and serum } \\
\hline 1 & $50.7 \pm 5.1$ & $47.3 \pm 6.2$ & $41.3 \pm 7.0$ & $48.2 \pm 3.9$ & $67.9 \pm 4.6$ & $69.3 \pm 6.0$ & $72.4 \pm 8.2$ & $64.9 \pm 8.1$ & $57.4 \pm 7.7$ & $47.4 \pm 2.9$ \\
\hline 3 & $14.1 \pm 0.7$ & $13.0 \pm 1.4$ & $12.9 \pm 0.9$ & $16.7 \pm 2.4$ & $43.8 \pm 3.7$ & $40.1 \pm 3.1$ & $32.7 \pm 4.0$ & $24.7 \pm 2.6$ & $18.0 \pm 1.4$ & $13.9 \pm 1.7$ \\
\hline 5 & $12.9 \pm 1.7$ & $12.6 \pm 0.6$ & $10.9 \pm 0.7$ & $13.2 \pm 1.4$ & $35.0 \pm 5.0$ & $27.4 \pm 3.0$ & $25.3 \pm 4.7$ & $21.4 \pm 3.8$ & $13.8 \pm 0.5$ & $13.0 \pm 1.0$ \\
\hline 7 & $13.4 \pm 0.5$ & $12.3 \pm 1.0$ & $11.3 \pm 0.6$ & $14.3 \pm 1.0$ & $36.1 \pm 4.1$ & $29.0 \pm 4.0$ & $27.4 \pm 3.2$ & $19.6 \pm 1.3$ & $15.0 \pm 1.7$ & $13.2 \pm 0.6$ \\
\hline 9 & $13.8 \pm 1.2$ & $13.0 \pm 0.8$ & $12.7 \pm 0.9$ & $15.1 \pm 1.9$ & $43.6 \pm 6.3$ & $32.4 \pm 2.7$ & $29.4 \pm 4.2$ & $24.3 \pm 1.7$ & $16.1 \pm 1.2$ & $13.4 \pm 0.7$ \\
\hline 11 & $22.1 \pm 2.9$ & $19.2 \pm 1.7$ & $16.3 \pm 0.9$ & $24.6 \pm 1.7$ & $49.0 \pm 3.8$ & $43.7 \pm 4.1$ & $37.0 \pm 4.0$ & $28.4 \pm 3.2$ & $23.4 \pm 1.9$ & $20.7 \pm 2.6$ \\
\hline \multicolumn{11}{|c|}{ (C) Normal plasma, shock serum } \\
\hline 1 & $40.0 \pm 3.7$ & $34.2 \pm 2.9$ & $37.4 \pm 3.8$ & $41.0 \pm 5.1$ & $39.0 \pm 2.7$ & $47.0 \pm 4.0$ & $43.1 \pm 4.1$ & $42.7 \pm 3.8$ & $39.8 \pm 3.7$ & $42.3 \pm 4.3$ \\
\hline 3 & $14.1 \pm 0.6$ & $11.7 \pm 1.1$ & $12.3 \pm 1.2$ & $14.2 \pm 0.9$ & $14.5 \pm 1.3$ & $13.7 \pm 1.7$ & $14.3 \pm 1.0$ & $13.8 \pm 1.4$ & $13.9 \pm 0.9$ & $14.9 \pm 1.3$ \\
\hline 5 & $13.0 \pm 0.4$ & $10.9 \pm 0.7$ & $11.8 \pm 0.9$ & $13.2 \pm 1.3$ & $13.4 \pm 1.4$ & $12.9 \pm 1.6$ & $13.5 \pm 1.9$ & $12.8 \pm 1.3$ & $13.2 \pm 2.0$ & $13.0 \pm 1.4$ \\
\hline 7 & $13.9 \pm 1.1$ & $11.4 \pm 0.4$ & $11.9 \pm 1.3$ & $13.8 \pm 1.1$ & $13.7 \pm 2.0$ & $13.3 \pm 1.3$ & $12.9 \pm 1.7$ & $13.4 \pm 1.2$ & $13.7 \pm 1.8$ & $13.0 \pm 0.6$ \\
\hline 9 & $14.6 \pm 1.0$ & $12.8 \pm 0.3$ & $12.3 \pm 0.7$ & $13.7 \pm 0.8$ & $14.0 \pm 1.2$ & $14.7 \pm 1.7$ & $14.7 \pm 2.0$ & $14.3 \pm 2.1$ & $15.1 \pm 0.9$ & $14.7 \pm 1.4$ \\
\hline 11 & $19.2 \pm 2.3$ & $16.4 \pm 2.1$ & $17.4 \pm 2.7$ & $22.1 \pm 4.0$ & $22.7 \pm 4.3$ & $19.0 \pm 3.7$ & $24.0 \pm 5.7$ & $23.6 \pm 4.9$ & $22.9 \pm 3.7$ & $23.0 \pm 4.5$ \\
\hline \multicolumn{11}{|c|}{ (D) Shock plasma, normal serum } \\
\hline 1 & $43.2 \pm 3.2$ & $39.0 \pm 4.0$ & $37.4 \pm 2.7$ & $39.2 \pm 3.4$ & $42.4 \pm 4.1$ & $38.9 \pm 6.0$ & $41.6 \pm 2.8$ & $42.4 \pm 1.7$ & $39.7 \pm 3.7$ & $40.9 \pm 2.4$ \\
\hline 3 & $13.7 \pm 1.7$ & $13.0 \pm 1.4$ & $12.4 \pm 0.7$ & $14.0 \pm 2.1$ & $26.1 \pm 3.9$ & $28.4 \pm 4.2$ & $24.2 \pm 3.0$ & $19.9 \pm 2.5$ & $14.7 \pm 2.9$ & $15.0 \pm 2.7$ \\
\hline 5 & $12.9 \pm 1.4$ & $12.4 \pm 1.2$ & $11.7 \pm 1.3$ & $13.4 \pm 1.4$ & $24.7 \pm 5.1$ & $21.7 \pm 4.9$ & $23.7 \pm 3.2$ & $17.5 \pm 2.0$ & $14.1 \pm 0.9$ & $13.2 \pm 2.7$ \\
\hline 7 & $13.8 \pm 0.7$ & $13.0 \pm 1.2$ & $11.5 \pm 0.8$ & $13.0 \pm 0.9$ & $23.4 \pm 2.4$ & $22.4 \pm 4.0$ & $20.1 \pm 3.2$ & $16.3 \pm 2.7$ & $13.9 \pm 0.9$ & $13.5 \pm 0.7$ \\
\hline 9 & $14.7 \pm 1.7$ & $13.8 \pm 0.9$ & $14.1 \pm 1.4$ & $15.4 \pm 0.9$ & $25.7 \pm 5.0$ & $24.8 \pm 4.7$ & $22.3 \pm 3.9$ & $18.0 \pm 2.1$ & $.14 .9 \pm 1.6$ & $14.8 \pm 1.3$ \\
\hline 11 & $20.7 \pm 2.8$ & $18.4 \pm 2.6$ & $17.9 \pm 2.0$ & $22.0 \pm 2.9$ & $32.4 \pm 4.1$ & $29.3 \pm 5.0$ & $26.4 \pm 4.1$ & $23.0 \pm 2.3$ & $20.9 \pm 3.2$ & $21.4 \pm 3.6$ \\
\hline
\end{tabular}

* Various combinations of plasma and serum were used. Human platelets, however, were used in all experiments. The figures given are averages and standard deviations for six experiments. One group of six rabbits provided data for the period from 0 to 2 hours; another for the period from 6 to 72 hours.

of streptokinase to serum (17). This technique essentially supplied information on the remaining profibrinolysin in the serum which could be activated by the addition of streptokinase. Thus, as used, it could probably be considered a test of utilization of profibrinolysin. b) Observation of the lytic activity of the rabbit serum when added directly to the fibrin plate (in a volume of $0.03 \mathrm{ml}$.). This technique and the following one gave information on the direct fibrinolytic activity of serum. c) A plasma clot method. Two-tenths $\mathrm{ml}$. of serum was added to 0.3 of rabbit plasma diluted with an equal volume of isotonic saline solution. The mixture was promptly clotted by the addition of $0.1 \mathrm{ml}$. of thrombin solution containing 100 National Institutes of Health (NIH) units per ml. and the behavior of the clot followed at various intervals of time.

The antifibrinolytic activity of serum was studied by means of a modified plate technique. ${ }^{2}$ Complement titer

2 Outline of method for the study of the antifibrinolytic activity of rabbit serum. The method is based on the ability of the antifibrinolysin of serum to prevent or oppose the digestion of a fibrin plate by activated fibrinoly- was determined by the method described in Boyd's monograph (18).

sin. Reagents: a) bovine fibrinogen prepared by the method of Milstone (19), 1.2 per cent solution in veronal saline buffer at $\mathrm{pH} 7.4$; b) bovine thrombin (Parke, Davis), $100 \mathrm{NIH}$ units in $1 \mathrm{ml}$. of isotonic saline; c) globulin fraction from human serum, $1 \mathrm{mg}$. per $\mathrm{ml}$. of isotonic saline; d) streptokinase (Lederle) dissolved in veronal saline buffer (1 $\mathrm{mg}$. in $1 \mathrm{ml}$.); e) rabbit serum, serially diluted with isotonic saline. Technique. Two per cent in volume of human euglobulin solution is added to a small volume of streptokinase solution. Two volumes of the mixture is then added to 98 volumes of fibrinogen solution. Ten $\mathrm{ml}$. of the latter mixture is rapidly transferred to a Petri dish $9 \mathrm{~cm}$. in diameter and immediately clotted by the addition of $1 \mathrm{ml}$. of thrombin solution. One drop $(0.03 \mathrm{ml}$.) of each dilution of serum tested is then deposited gently on different areas of the plate, which is then incubated at $37^{\circ} \mathrm{C}$. for 24 hours. At the end of incubation the plate is lysed except for the areas where serum has been deposited. Evaluation. The diameters of the surfaces where no lysis has occurred are measured and their areas calculated. The values obtained 


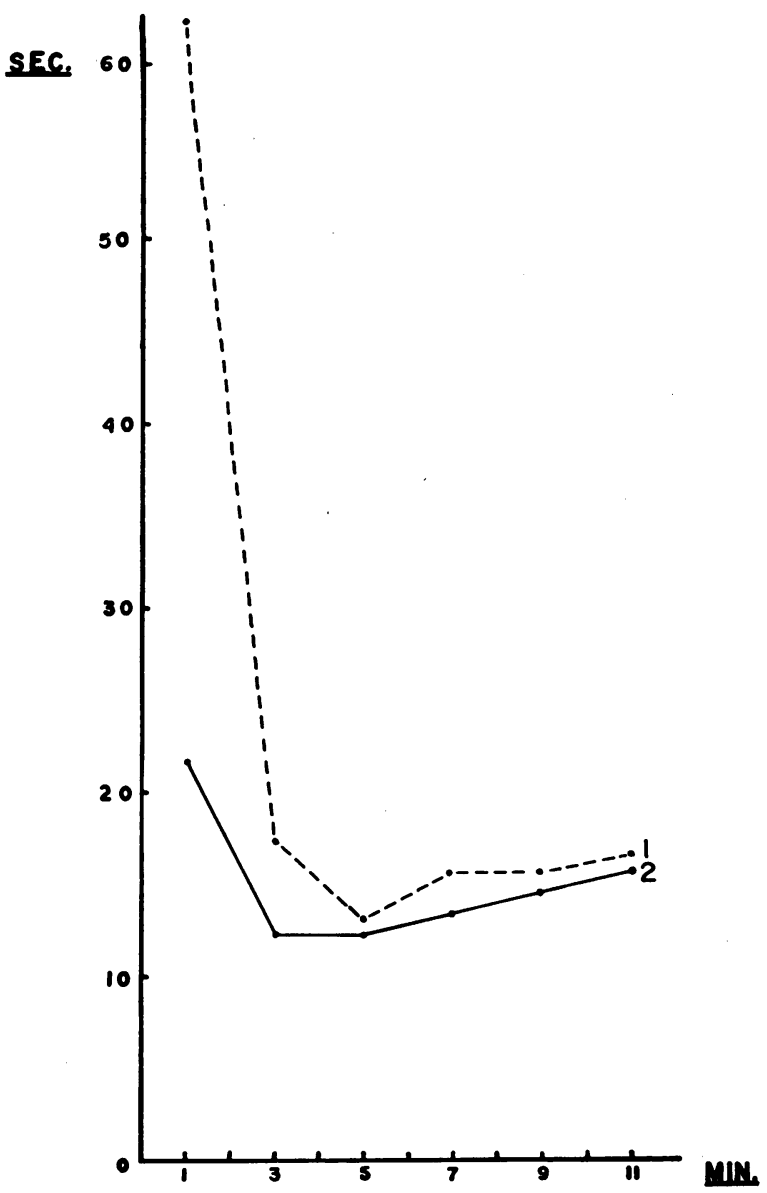

Fig. 3. The Clot Accelerating Property in Vivo of the Serum from a Rabbit in the Early Phase of HemorRhagic Shock InJected into a Normal Animal

Thromboplastin generation test, using the transfused animal's own plasma and serum, and human platelets (see legend to Figure 2). Figure shows thromboplastin generation 1) prior to injection of serum, and 2) 30 minutes after the injection of serum from the animal in hemorrhagic shock.

All animals were killed ${ }^{3} 3,24$ or 96 hours after the establishment of hemorrhagic shock. Autopsy was performed immediately. After recording the macroscopic findings, thin slices of liver, lung, adrenal and kidney are compared with those obtained using various dilutions of a pool of serum from various normal animals. Undiluted pooled serum is conventionally assigned 100 per cent activity, and the various serial dilutions are assigned corresponding percentage values. Interpolation on logarithmic paper supplies direct reading values. Full details of the technique are being published elsewhere (20).

3 One of the three following techniques was used: 1) intra-arterial injection of approximately $30 \mathrm{ml}$. of air ; 2) intravenous injection of approximately $30 \mathrm{ml}$. of air; 3) inhalation of $\mathrm{CH} \mathrm{Cl}$. tissue were fixed in either Zenker's, or 10 per cent formalin solutions. Sections were then stained with hematoxylin-eosin, phloxine-methylene blue or phosphotungstic acid hemotoxylin stains.

\section{RESULTS}

\section{Blood coagulation changes}

It should be pointed out that the time relationship between hemorrhage and shock shown in the figures was somewhat arbitrary. In each instance, shock seemed to follow bleeding in short order of time, lasting between four and 10 hours after cessation of hemorrhage. Occasionally there was a more prompt recovery. In all cases, however, the changes observed in the coagulation mechanism showed a similar trend. Their behavior allowed the distinction of three phases: $a$ ) an early, $b$ ) a late and $c$ ) a recovery phase.

a) Early phase. This lasted approximately one hour and, thus, at least one-half hour be-

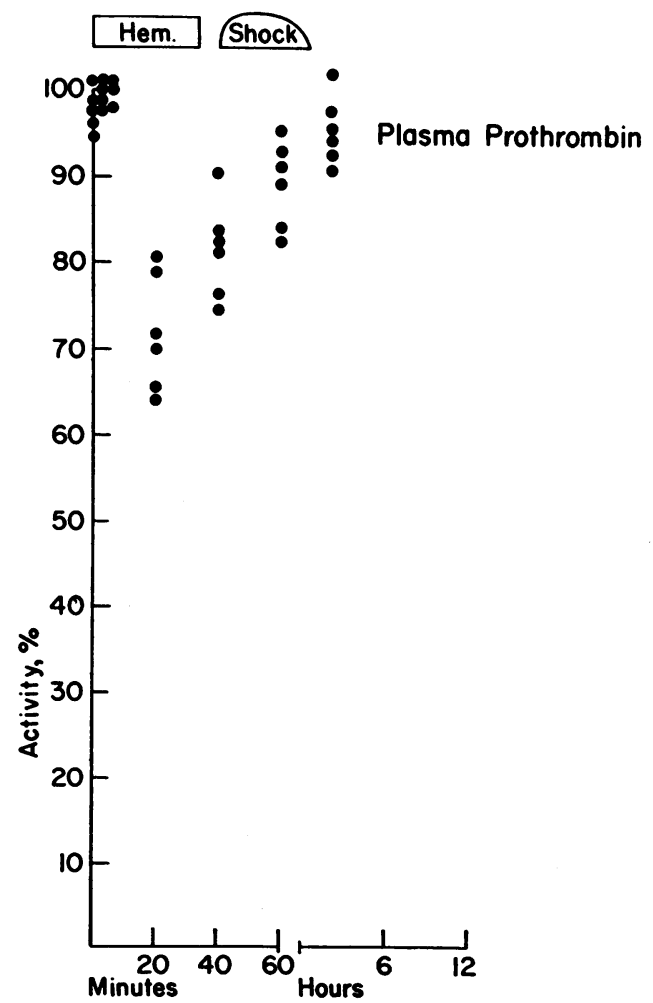

Fig. 4. Plasma Prothrombin Percentage Activity During Hemorrhagic Shock in Rabbits (See TEXT)

Initial values, as for all figures, are prehemorrhagic values. 


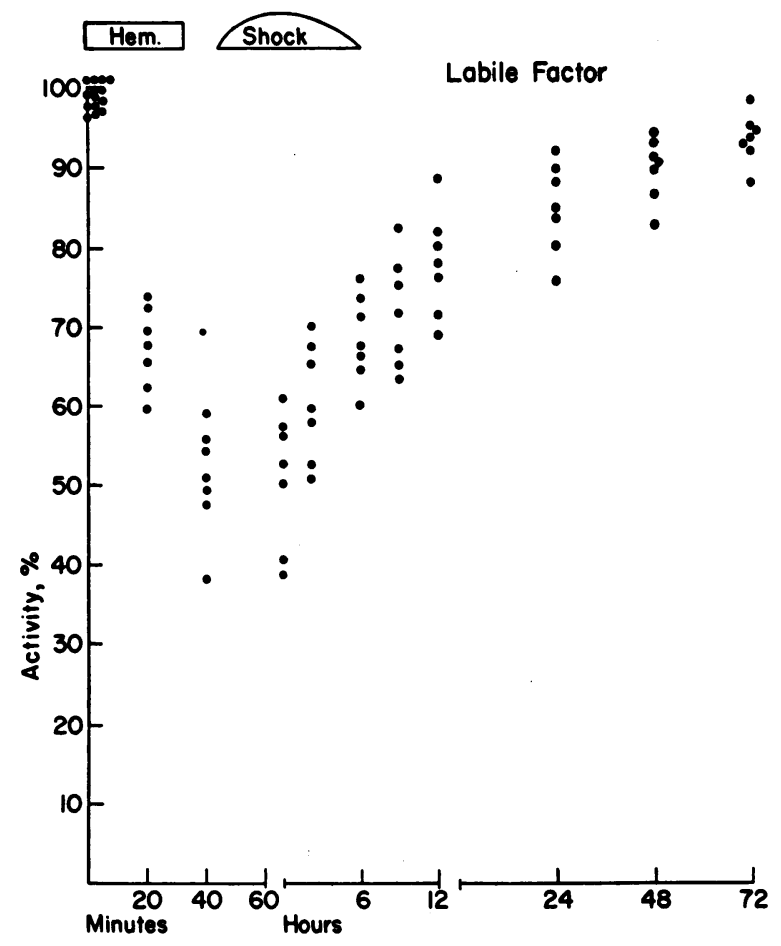

Fig. 5. Plasma labile Factor Activity During Hemorrhagic Shock in Rabbits (See Text)

yond the termination of bleeding. Changes involved many of the clotting agents. Most significant perhaps was the development of a strong coagulation accelerating factor.

1) Platelets (Figure 1). Their number rose rapidly as bleeding began and doubled within 15 to 25 minutes. Platelets also became smaller and showed numerous dendrites.

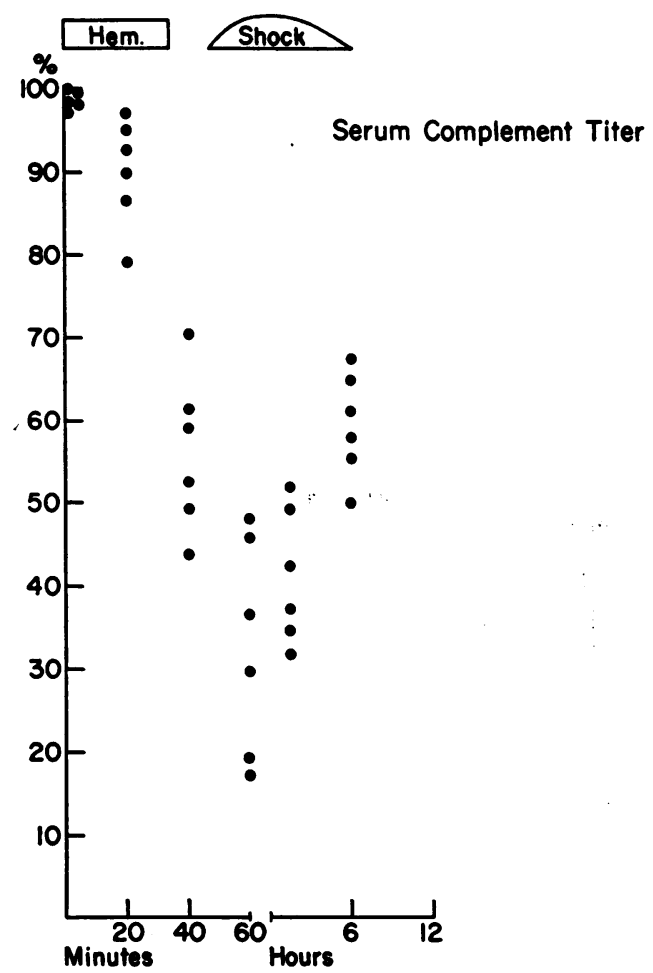

Fig. 6. Serum Complement Titer During HemorRHAGIC SHOCK IN RABBITS

Results were entirely normal at 12 hours.

2) Generation of thromboplastin. The speed of formation and total yield of thromboplastin were increased. Theoretically, this may be due to changes in platelets, plasma or serum. Platelets, being added in excess in all our tests, could be excluded in the interpretation of the results. As discussed in the legend to Figure 2 and shown

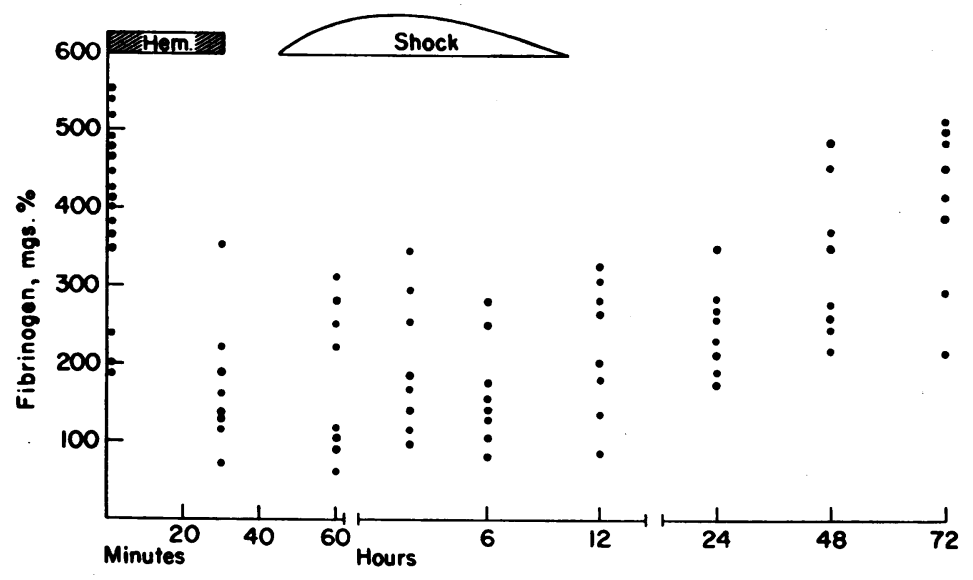

Fig. 7. Plasma Fibrinogen Level During and Following Hemorrhagic Shock in Rabbits (See Text) 


\section{HEMORRHAGIC SHOCK}
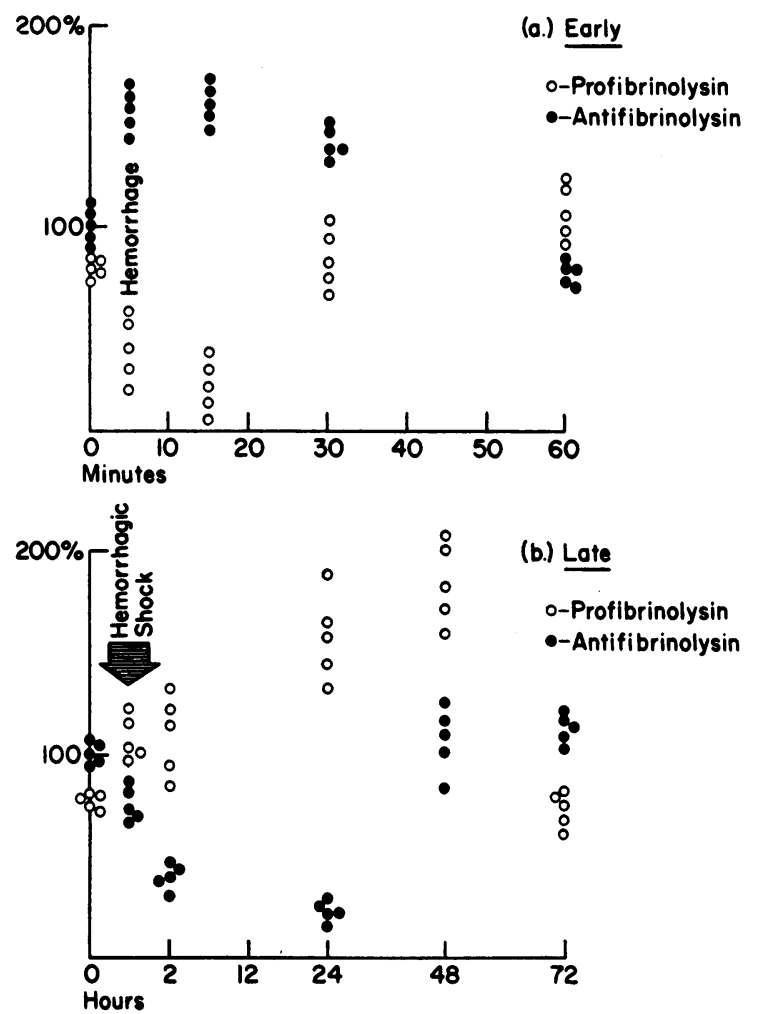

Fig. 8. The Fibrinolytic System in Hemorrhagic Shock: a) Early Phase; B) Late Phase (See TEXT)

in Table I, however, the greater yield and accelerated formation of thromboplastin were due to changes in plasma and serum, both, but especially the serum, containing powerful activators. The activators were active in vivo as well as in vitro. Figure 3 illustrates an in vivo experiment to support this conclusion. Fifty $\mathrm{ml}$. of blood was collected from a rabbit and the procedure repeated one hour later. Both samples were allowed to clot and the serum separated and incubated at $37^{\circ} \mathrm{C}$. for four additional hours to make it free of thrombin activity. Each sample of serum was then injected into normal animals. Only moderate acceleration of the formation of thromboplastin followed the injection of the serum collected prior to bleeding; the acceleration was very marked after the injection of the serum collected during hemorrhagic shock.

3) Activity of plasma prothrombin (stable and labile factors). The prothrombin activity of plasma was only slightly affected (Figure 4). Studies on the activity of stable serum factor(s) involved in the conversion of prothrombin to thrombin (proconvertin activity) gave dubious results because of the presence of a strong clotaccelerating substance in the serum. The activity of plasma labile factor was significantly decreased (Figure 5). This is usually seen during activation of fibrinolysis or during active intravascular clotting. In the first instance, the agent is destroyed; in the second, it is converted to an accelerator which is found in serum. We have no data, at the present time, to conclude whether the clotting accelerator found in the serum of our experimental animals could be identified with "activated" labile factor. In any case, the presence of a clotting accelerator in plasma probably compensated for the drop in labile factor activity, thus explaining the overall minor change in the Quick plasma prothrombin time.

4) Serum complement. ${ }^{4}$ There was a fairly short-lived fall in its titer (Figure 6).

5) Plasma fibrinogen level fell as soon as bleeding began. The low level of fibrinogen persisted for several hours after bleeding had been discontinued (Figure 7).

6) The fibrinolytic system (Figure 8a). There was a prompt drop in the profibrinolytic activity of serum and a corresponding rapid increment of the serum antifibrinolytic activity. There was at no time evidence of direct fibrinolytic activity of the serum on bovine fibrin plate or human plasma clots.

b) Late phase. This phase lasted between one and 48 hours after termination of hemorrhage, extending into the phase of recovery.

1) Platelets. After the initial rise in the early phase, their number fell rapidly, reaching a minimum value between 2 and 12 hours (Figure 1 ).

2) Generation of thromboplastin (Figure 9). This became slow and incomplete. An analytical study indicated that the defect in generation of thromboplastin was probably due to a complex combined depletion of the plasma and serum factors involved (Table I). It was noted that serum no longer accelerated the formation of thromboplastin when added to normal plasma and platelets.

\footnotetext{
4 Determination performed by Miss Rose $\mathrm{H}$. Mele.
} 


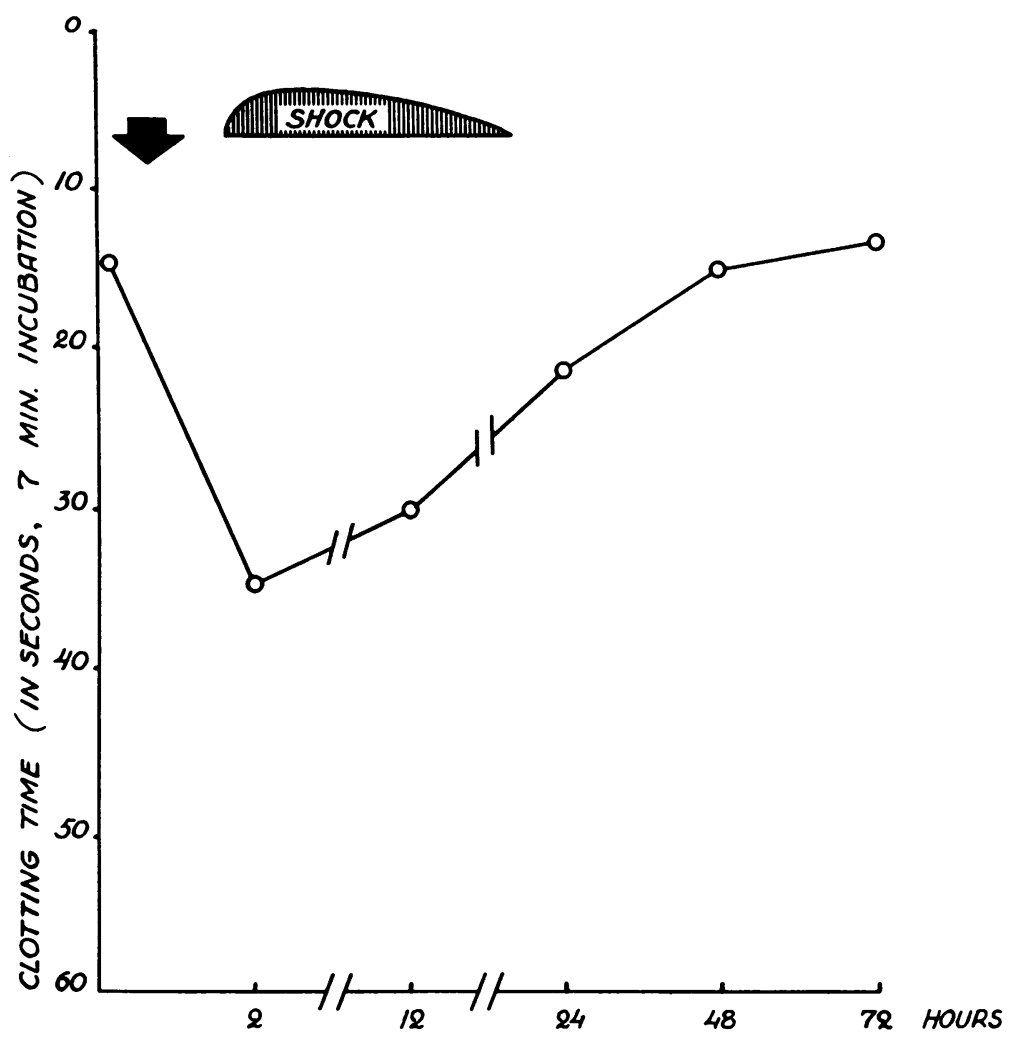

Fig. 9. Thromboplastin Generation Test in the Late Phase of Hemorrhagic Shock: A Single Experiment

Results are those obtained at seven minutes of incubation of the reacting mixture, composed of the animal's serum and plasma and of human platelets.

3) Activity of plasma prothrombin and labile factor (Figures 4 and 5). The activity of plasma prothrombin, still slightly low at the beginning of this phase, rose rapidly to normal figures within a few hours. The activity of plasma labile factor remained below normal during this phase.

4) Plasma fibrinogen level remained very low for at least 12 hours after termination of bleeding, then began to rise (Figure 7).

5) The fibrinolytic system continued to show considerable changes (Figure $8 \mathrm{~b}$ ) for at least 48 additional hours. The findings were exactly the opposite of those observed in the early phase. The serum profibrinolytic activity was greatly increased, with a complementary fall in activity of serum antifibrinolysin. Again, no direct fibrinolytic activity could be demonstrated.

c) Recovery phase. This phase does not require a detailed description. All values returned to normal within 48 and 72 hours.

\section{Anatomical and histological findings}

Control animals showed no significant macroscopic findings, with the exception of occasional, small superficial petechiae and ecchymotic areas of the lungs. In contrast, animals which had undergone hemorrhagic shock showed evident areas of lung hemorrhage, decreasing in severity from the third to the ninety-sixth hour. The areas were often triangular in shape with the base toward the pleural surface of the lung and the apex on the hilus. At microscopic examination ${ }^{5}$ of the lung in animals killed within three hours, the arterial vessels were generally collapsed with a small amount of blood in their lumina. There was

5 We wish to thank Dr. Joseph J. Giammalvo, Department of Pathology, Tufts University School of Medicine, who kindly reviewed over two hundred sections and interpreted them. Dr. James H. Graham and Dr. Salvatore Allegra, Saint Elizabeth's Hospital, Boston, kindly helped in preliminary observations. 


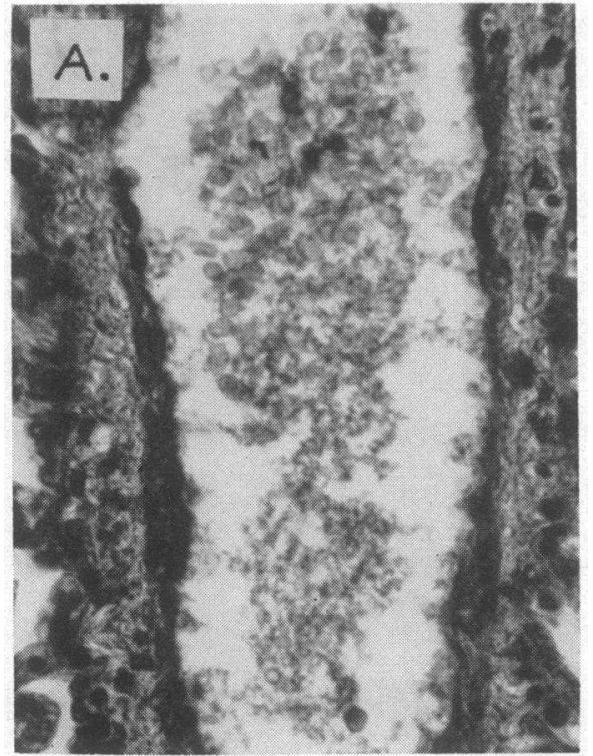

Fig. 10A. Histologic Features of Hemorrhagic Shock in Rabbit Sacrificed Three Hours After Establishment of SHock

Pulmonary vessel, containing erythrocytes and "granules" of material with the staining properties of fibrin (phosphotungstic acid hematoxylin stain, $\times 400$ ).

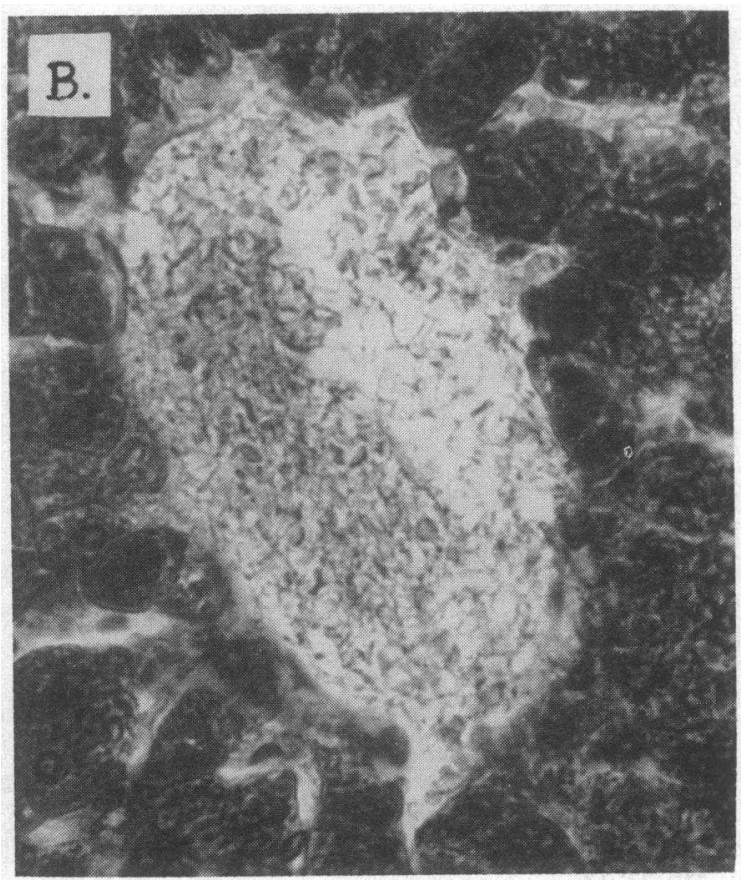

Fig. 10B. Histologic Features of Hemorrhagic Shock in Rabbit Sacrificed Three Hours After Establishment of Shock

Hepatic vessel, containing erythrocytes, amorphous material and fine filaments of material with the staining properties of fibrin (phosphotungstic acid hematoxylin stain, $\times 800$ ).

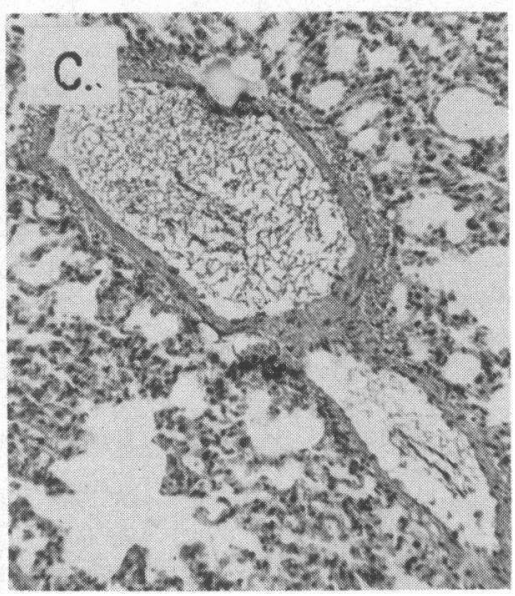

Fig. 10C. Histologic Features of Hemorrhagic Shock in Rabbit Sacrificed Three Hours After Establishment OF SHOCK

Pulmonary vessel containing thick fibers of fibrin (hematoxylin-eosin stain, $\times 120$ ).

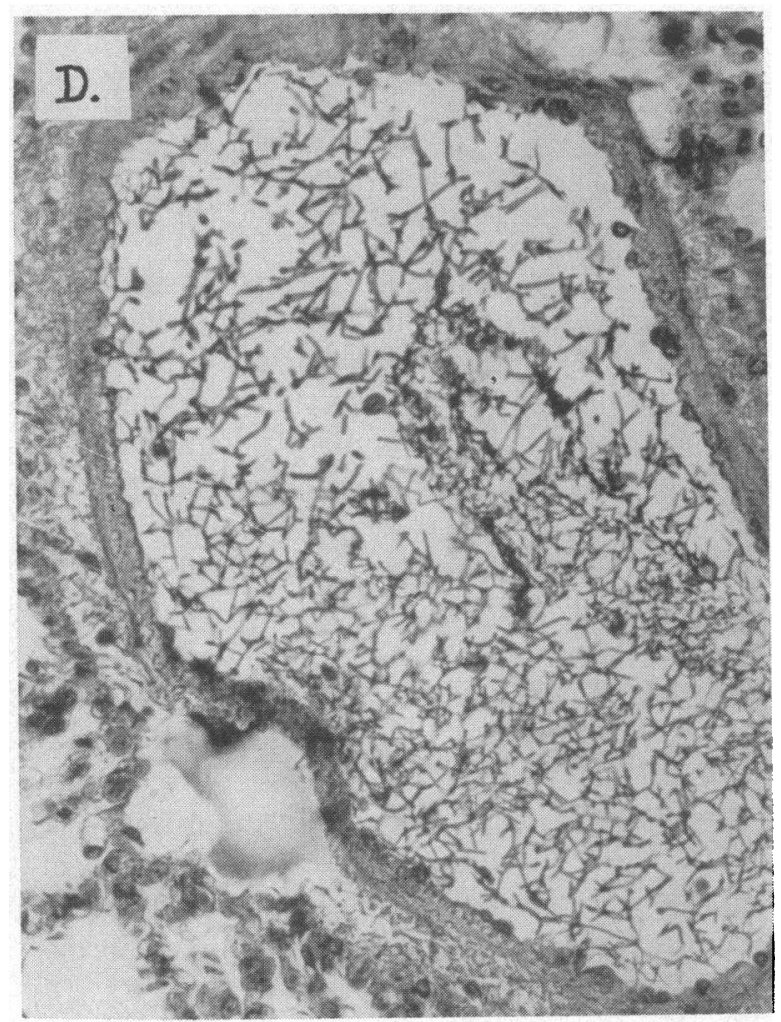

Fig. 10D. Histologic Features of Hemorrhagic Shock in Rabbit Sacrificed Three Hours After EstablishMENT OF SHOCK

Magnification of C $(\times 400)$. 
diffuse intra-alveolar hemorrhage, and moderately severe edema and focal atelectasis were generally present at the periphery. The tertiary bronchi were partially filled with blood within which clusters of fibrin were present. Some of the major veins were filled with blood mixed with fibrin clots. The histologic appearance of fibrin varied from granules (Figure 10a) to fine filaments (Figure 10b) to thick fibers (Figure 10c). The identification of these structures with fibrin was confirmed by their reaction with phosphotungstic acid hematoxylin and phloxinemethylene blue stains. Filaments and fibers were interwoven and surrounded granular masses of amorphous material resembling clumps of platelets. No organized thrombi were noted. A similar picture was observed within the venous vessels of liver and kidney. Findings were negligible after 24 hours and had regressed entirely after 96 hours.

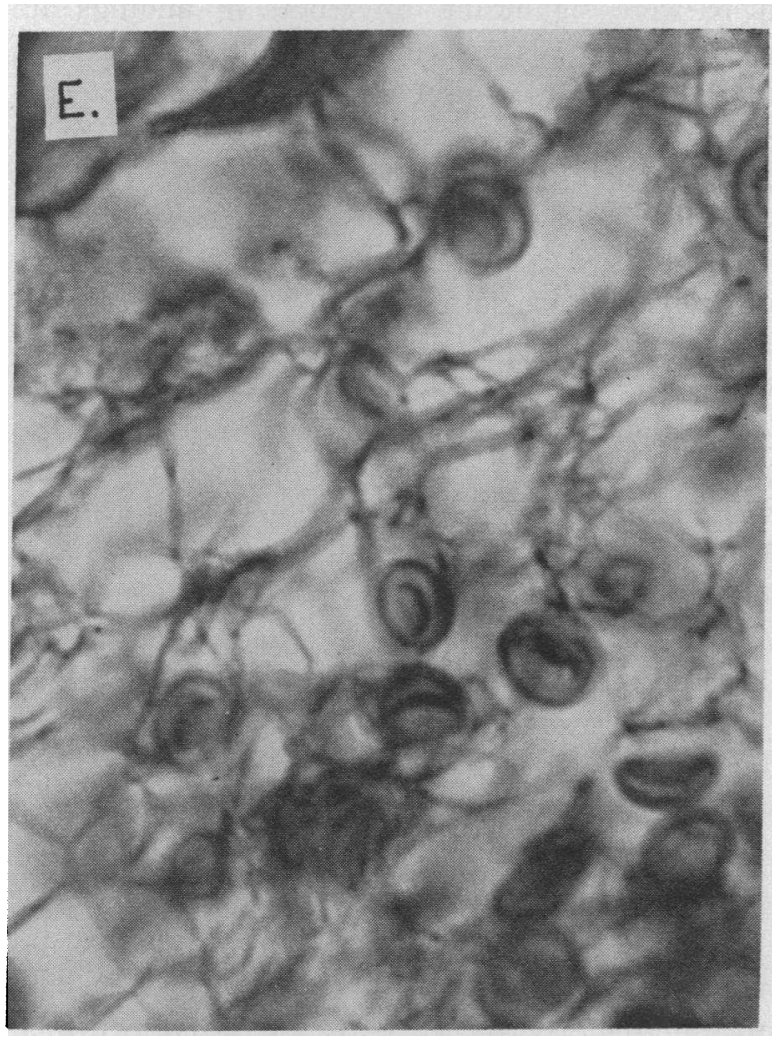

Fig. 10E. Histologic Features of Hemorrhagic Shock In Rabbit Sacrificed Three Hours After Establishment OF SHOCK

Hepatic vessel containing erythrocytes and fibrin fibers (phosphotungstic acid hematoxylin stain, $\times 1,500$ ).

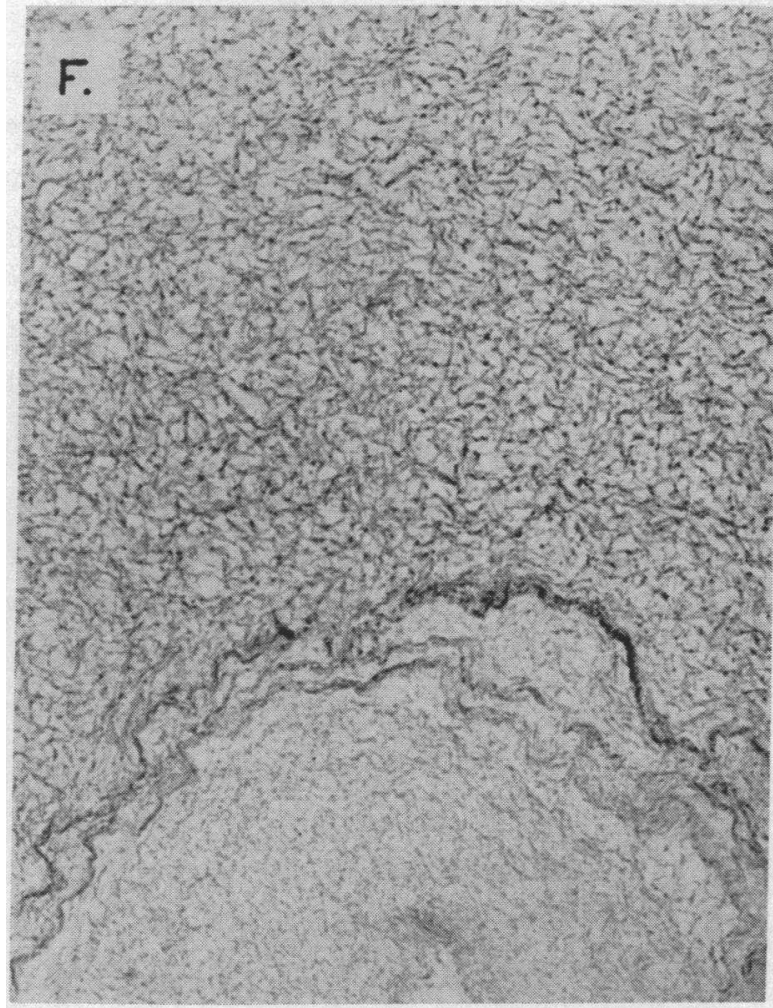

Fig. 10F. Histologic Features of Human Plasma Containing Platelets Clotted by Addition of Bovine Thrombin

Appearance of fibrin strands in the human plasma clot (hematoxylin-eosin, $\times 400$ ). Note similarity to filaments in $\mathrm{C}$.

\section{Influence of splenectomy on the hemostatic breakdown of hemorrhagic shock}

As mentioned, splenectomy prevents the acceleration of the clotting time in dogs during experimental hemorrhagic shock (4). Accordingly, it was decided to evaluate the effects of splenectomy on the changes in the coagulation mechanism of bled rabbits. Splenectomy was performed in four rabbits under pentothal anesthesia ${ }^{6}$ by standard procedure. Three weeks after splenectomy, the same observations were carried out as for intact animals. Findings were much different. Platelets and fibrinogen level decreased only slightly during bleeding (possibly because of blood loss). Platelets and fibrinogen, in fact, rose markedly 24 and 48 hours later, respectively (Figure 11). There was decreased yield and

- Performed by Dr. Harman van Lessen (Bremerhaven, Germany) and Dr. Hector Marin. 


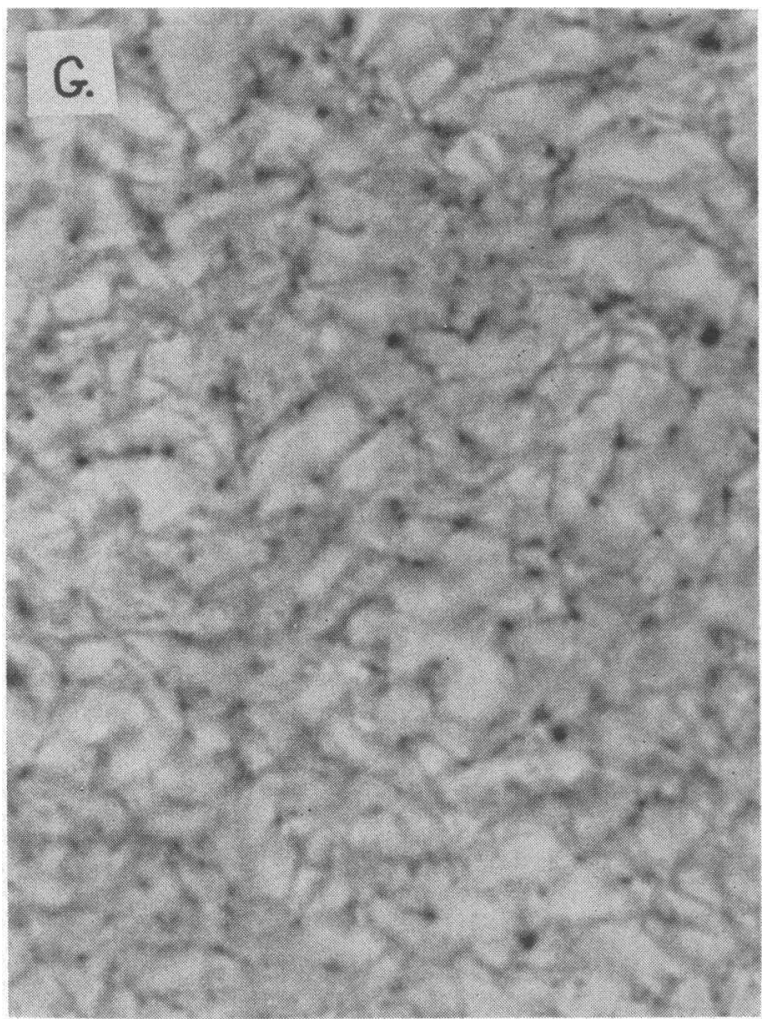

Fig. 10G. Histologic Features of Human Plasma Containing Platelets Clotted by Addition of Bovine THROMBIN

Appearance of fibrin strands in the human plasma clot $(\times 1,200)$. Note similarity with findings in D.

speed of formation of thromboplastin for the first two to eight hours. The serum of the animal contained no clot accelerating agents as in the intact rabbits. Changes in activity of plasma prothrombin and labile factor were negligible. Fibrinolytic activity decreased slightly for many hours; the antifibrinolytic activity behaved in reciprocal manner to fibrinolysin (Figure 12). In any case, as discussed in the legends of Figures 11 and 12, changes were less significant than those observed in the intact animal. The autopsy performed three hours after bleeding showed no macroscopic hemorrhages in the lung or other organs. Microscopic sections of lung, liver and kidney showed numerous intravascular clumps of amorphous material which might have represented platelets. The findings were probably abnormal since they were not present in control animals. Yet no significant intravascular deposition of fibrin was seen, as in the intact animal.

\section{DISCUSSION}

The present work was originally planned to explain some of the abnormalities of the hemostatic mechanism previously observed during massive bleeding with multiple replacement transfusions in patients undergoing surgery $(21,22)$. A biphasic behavior was then recorded. Exaggerated and faster formation of thromboplastin, thrombocytosis, fibrinogenopenia and elevated antifibrinolytic activity were observed in an early phase. Severe breakdown of the hemostatic process followed, with marked thrombocytopenia, fibrinogenopenia and exalted fibrinolytic activity. It was felt that the findings might have been due to the effect of hemorrhage (21). The conclusion is supported by the results of the studies reported here, as the present findings correlate well with the previous clinical observations

An attempt was made in the course of this paper to divide the sequence of events into various phases (Figure 13). This was necessary since there were significant differences in findings at various intervals of time. This consideration might explain the discrepancies observed in the study of patients who develop hemorrhagic shock. In each phase, three significant factors were to be considered: 1) the blood loss; 2) the occurrence of intravascular clotting; and 3) the rapid rate of production of clotting factors by the body and the transfer of proteins from tissue pools to the circulating plasma.

The blood loss seemed important in an early phase, since it induced rapid subtraction of clotting factors from the blood stream. Yet, a number of findings indicated that blood loss alone might not be invoked as an overall explanation. Fibrinogen and other clotting factors remained low for hours, when synthesis and shifting from tissue pools to plasma should have induced an opposite trend. More important, the accelerated rate of formation and increased yield of plasma thromboplastin, and the appearance of a clot accelerating factor during the early phase of hemorrhagic shock (the nature of which is being investigated) seemed to indicate "increased coagulability" of the blood. This hypothesis was further substantiated by the histologic findings of fibrin deposition within the blood stream. Thus, intravascular clotting was at least one (if not the most 


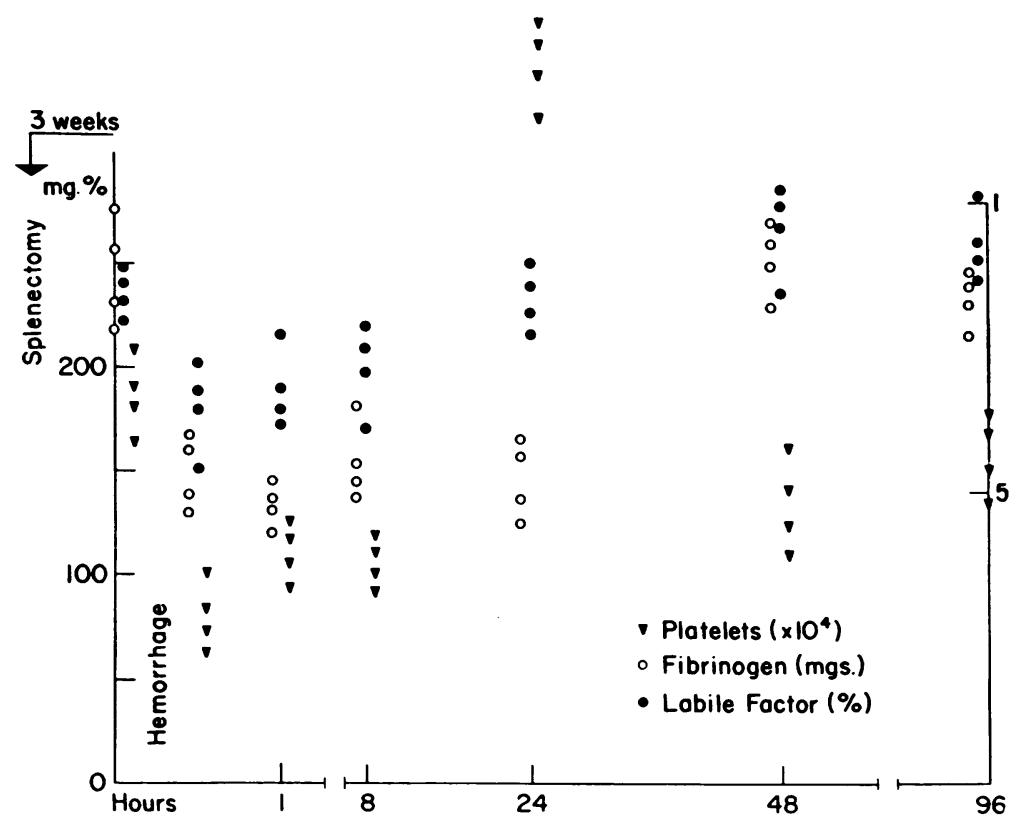

Fig. 11. The Coagulation Factors in a Splenectomized Rabbit During HeMORRH AGIC ShOCK

Using Figures 1 and 7 as comparison, note: a) the initial high platelet count, to be expected three weeks after splenectomy; b) the lack of early elevation of platelets and their remarkable rise during the late phase of hemorrhagic shock; and c) the fairly minor fall of fibrinogen level as compared to the extreme fibrinogenopenia of the intact animal.

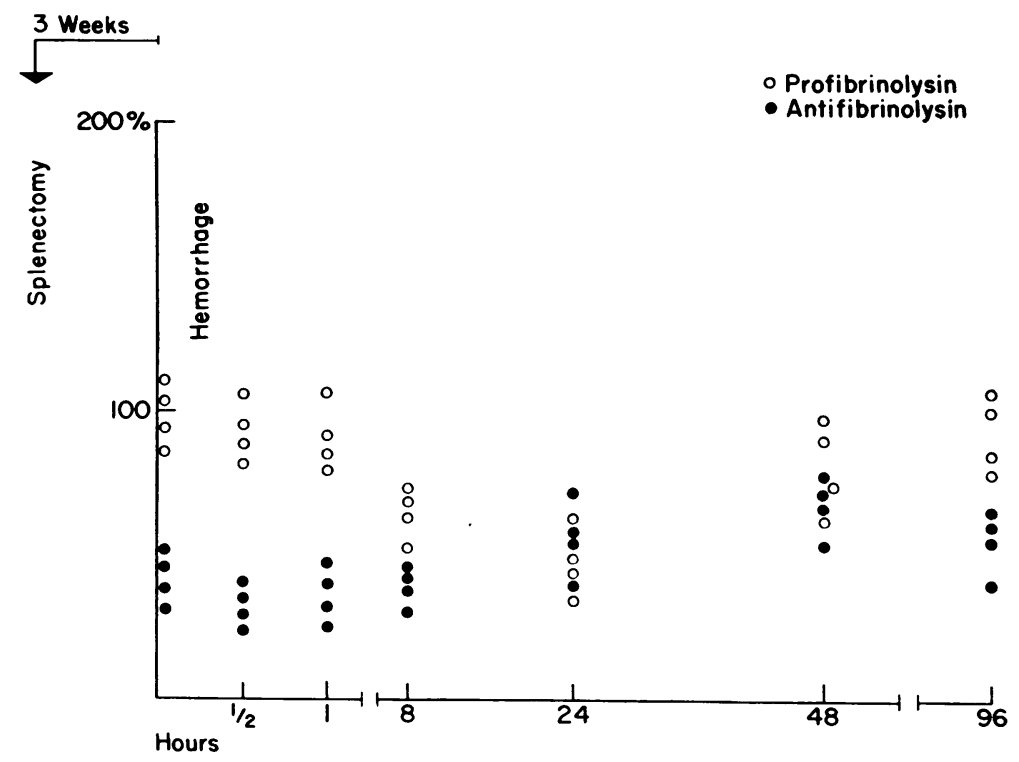

Fig. 12. The Fibrinolytic System Dering Hemorrhagic Shock in Four Splenectomized RabBits

Using Figure 8 as comparison, note: a) lack of significant changes in the early phase, and b) the minor, possibly insignificant, changes in the late phase. 


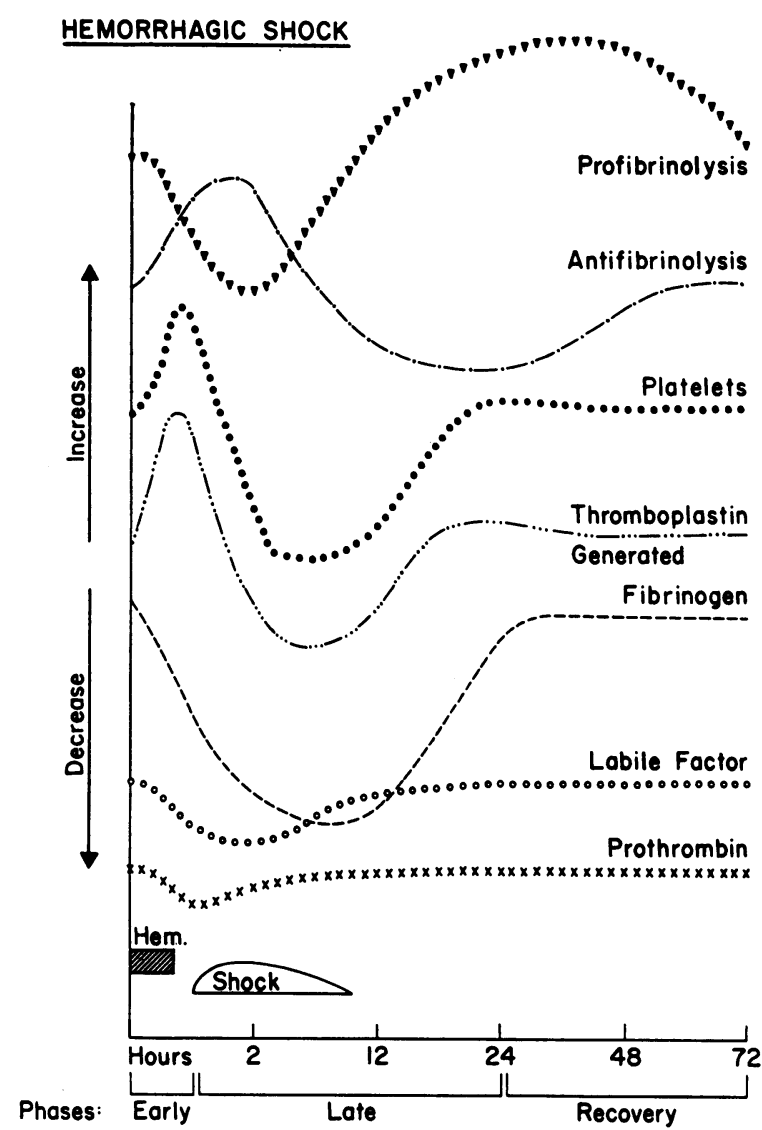

Fig. 13. Hemorrhagic Shock: A Summary

This schematic figure shows the variations of many of the clotting factors in relation to time (see text). Curves are based on the mean values in 12 animals selected at random, six of which were studied in the early, and six in the late and recovery phases.

important) reason for further depletion of clotting factors observed in the late phase of hemorrhagic shock. The clotting agents might have been used in the formation of multiple intravascular clots which were observed in our study. Intravascular coagulation might have also played a role in the establishment of "irreversible shock." Why lung, liver (and kidney) were the organs where most of the deposition of fibrin was histologically evident cannot be explained with certainty. It could be related to the function of these organs as filters for the general and mesenteric circulation.

As it is generally assumed that the process of blood coagulation is a delicate balance between forces of clot formation and forces of clot lysis, it was not surprising that important changes in the fibrinolytic system occurred in hemorrhagic shock, together with the changes in activity, number and concentration of various clotting factors. These changes were difficult to interpret. There was a late rise in serum profibrinolytic activity which was, on the contrary, quite low in the early phase of shock. This suggested early consumption of profibrinolysin in vivo and, thus, activation of fibrinolysin which, then, may have followed in the wake of intravascular clotting. Antifibrinolysin had a reciprocal behavior, possibly neutralizing the fibrinolytic activity and thus explaining the lack of direct fibrinolytic activity of the sera in vitro. It is difficult to reject the temptation of interpreting these changes as expression of a defense mechanism against extensive thrombosis.

Finally, of great interest for the interpretation of the hemostatic changes associated with hemorrhagic shock was the failure of these changes to develop in animals whose spleen had been recently removed. There was no evidence of formation of clot accelerating factors nor of important changes in the fibrinolytic system, such as were observed in the intact animal. From a histologic viewpoint, there was no intravascular deposition of fibrin. Possibly, findings could be explained simply by the loss of formed blood elements and of clotting factors through bleeding. On the basis of these results, it appeared difficult to exonerate a mechanism of splenic contraction in the pathogenesis of the intravascular clotting of hemorrhagic shock. As already postulated by $\mathrm{McClintock}$ and Magers, the splenic contraction which followed bleeding might have caused emmission into the blood stream of a clot-promoting factor. This was likely to be a tissular splenic thromboplastin or a thromboplastic material from platelets lysed in the spleen.

\section{SUM MARY}

1. Rabbits bled until development of shock showed significant alterations of the hemostatic process. Various phases were recognized. A state of "hypercoagulability" of the blood developed at first, as indicated by thrombocytosis, accelerated generation of thromboplastin, and rapidly instituted fibrinogenopenia. Plasma loss was, at least in part, responsible for the latter (early phase). As the hemorrhagic shock deep- 
ened, even after bleeding was stopped, there was a complete hemostatic breakdown. Platelets, fibrinogen and other coagulation factors were depleted. Fibrinolysis also developed, possibly as a mechanism of defense against intravascular deposition of fibrin (late phase). The various clotting factors later returned to normal values in variable periods of time if the hemorrhage was arrested and the state of shock regressed (recovery phase).

2. Histologic studies showed significant intravascular deposition of fibrin, possibly of platelets, in the vessels of lung, kidney and liver. This suggested widespread intravascular clotting.

3. Previous splenectomy mitigated the severity and duration of the hemostatic changes.

4. There was a significant correlation between these experimental results and some findings of the severe hemostatic breakdown in the course of hemorrhagic shock in man.

\section{ACKNOWLEDGMENT}

The authors wish to acknowledge the assistance of $\mathrm{Dr}$. Alejandro Arce $Q$. (Asuncion, Paraguay), Fellow of the Guggenheim Foundation, in the evaluation and confirmation of many experimental results.

\section{REFERENCES}

1. Stefanini, M. Fibrinolysis and "fibrinolytic purpura." Blood 1952, 7, 1044.

2. Hewson, W. in The Works of William Hewson, F.R.S., G. Gulliver, Ed. London, Sydenham Soc., 1846 , p. 46.

3. von den Velden, R. Blutverlust und Blutgerinnung. Naunyn-Schmiedeberg's Arch. exp. Path. Pharmak. 1909, 61, 37.

4. McClintock, J. T., and Magers, E. Coagulation time following hemorrhage after splenectomy. Proc. Soc. exp. Biol. Med. (N. Y.) 1926, 24, 203.

5. Gray, H., and Lunt, L. K. Factors affecting the coagulation time of blood: V. Effects of hemorrhage before and after exclusion of abdominal circulation, adrenals, or intestines. Amer. J. Physiol. 1914, 34, 332.
6. Shafiroff, B. G. P., Doubilet, H., Siffert, R., and Co Tui. Effect of hemorrhage on normal and hypocoagulable blood and lymphs. Amer. J. Physiol. 1943, 138, 753.

7. Smith, J. J., Hartwick, J. P., and Regan, M. J. Coagulation mechanism in hemorrhagic shock (abstract). Fed. Proc. 1957 16, 120.

8. Crowell, J. W., and Read, W. L. In vivo coagulation -A probable cause of irreversible shock. Amer. J. Physiol. 1955, 183, 565.

9. Warren, R., Lauridsen, J., and Belko, J. S. Alterations in numbers of circulating platelets following surgical operation and administration of adrenocorticotropic hormone. Circulation 1953 7, 481.

10. de Takats, G. Sensitized clotting time; simple test for bedside study of clotting mechanism. J. Amer. med. Ass. 1951, 146, 1370.

11. Wiggers, C. J. Physiology of Shock. New York, Commonwealth Fund Publ., 1950.

12. Stefanini, M., and Dameshek, W. The Hemorrhagic Disorders. New York, Grune \& Stratton Inc., 1955, p. 286.

13. Biggs, R., and Douglas, A. S. The thromboplastin generation test. J. clin. Path. 1953, 6, 23.

14. Quick, A. J. The Hemorrhagic Diseases and the Physiology of Hemostasis. Springfield, Ill., Charles C Thomas, 1942, p. 312.

15. Owren, P. A. The diagnostic and prognostic significance of plasma prothrombin in factor $\mathrm{V}$ levels in parenchymatous hepatitis and obstructive hepatitis. Scand. J. clin. Lab. Invest. 1949, 1, 131.

16. Wolf, P. A modification for routine laboratory use of Stefanini's method of estimating factor $\mathrm{V}$ activity in human oxalated plasma. J. clin. Path. 1953, 6, 34.

17. Astrup, T., and Müllertz, S. The fibrin plate method for estimating fibrinolytic activity.. Arch. Biochem. 1952, 40, 346.

18. Boyd, W. C. Fundamentals of Immunology, 3rd ed. New York, Interscience Publishers, Inc., 1956.

19. Milstone, J. H. Three-stage analysis of blood coagulation. J. gen. Physiol. 1948, 31, 301.

20. Turpini, R., and Stefanini, M. In preparation.

21. Stefanini, M., Mednicoff, I. B., Salomon, L., and Campbell, E. W. "Thrombocytopenia of replacement transfusion": A cause of surgical bleeding (abstract). Clin. Res. Proc. 1954, 2, 61.

22. Stefanini, M. Hemorrhagic tendency following massive transfusions at surgery. Proc. VIth Congress, Int. Soc. Blood Transfusion (Boston, Sept. 3, 1956). Basel, S. Karger, 1955, p. 78. 